\title{
The NISPI framework: Analysing collaborative problem-solving from students' physical interactions
}

\author{
Mutlu Cukurova ${ }^{\mathrm{a}}$, Rose Luckin ${ }^{\mathrm{a}}$, Eva Millán ${ }^{\mathrm{b}}$, Manolis Mavrikis $^{\mathrm{a}}$ \\ ${ }^{a}$ UCL Knowledge Lab, University College London, United Kingdom \\ ${ }^{b}$ ETSI Informática, University of Málaga, Spain
}

\begin{abstract}
Collaborative problem-solving (CPS) is a fundamental skill for success in modern societies, and part of many common constructivist teaching approaches. However, its effective implementation and evaluation in both digital and physical learning environments are challenging for educators. This paper presents an original method for identifying differences in CPS behaviours when groups of students are taking part in face-to-face practice-based learning (PBL). The dataset is based on high school and university students' hand position and head direction data, which can potentially be automated deploying existing multimodal learning analytics systems. The framework uses Nonverbal Indexes of Students' Physical Interactivity (NISPI) to interpret the key parameters of students' CPS competence. The results show that the NISPI framework can be used to judge students' CPS competence levels accurately based on their non-verbal behaviour data. The findings have significant implications for design, research and development of educational technology.
\end{abstract}

Keywords: Collaborative Learning, Problem-solving, Behaviour pattern differences, Practice-based learning, Indexes of physical interactivity

\section{Introduction}

Collaborative problem-solving (CPS) is a fundamental skill for modern societies to function and it should be supported and practised in Education systems across the globe. Perhaps, as the significance of CPS is clear to most educators, it is part of many common constructivist teaching approaches including problem-based learning, inquiry-based learning, projectbased learning, and practice-based learning. It is common to see situations 
in which learners work in unison to solve a problem during these teaching approaches, and perhaps that is why these constructivist teaching approaches are considered to have the potential to help foster the 21st-century skills we require of young people. For some decades now, there have been strong advocates of these teaching approaches in Education, arguing their merits in achieving such high-tier learning objectives (Montessori, 1965; Barron \& Darling-Hammond, 2010). However, existing evidence on the effectiveness of these methods to satisfy their learning outcomes is rare (Klahr \& Nigam, 2004), and they have been harshly criticised by some researchers as not being effective pedagogical approaches (Kirschner et al., 2006; Mayer, 2004).

According to Blikstein and Worsley (2016), this lack of evidence may stem from these pedagogical approaches' notoriously dynamic and laborious structures and commonly used standardised measurement method's lack of ability to detect impacts on students' skill development. However, the most recent developments in sensor technologies and learning analytics methodologies can help generate unique information about what happens as groups of students are engaged in constructivist pedagogies. Distinctions in student behaviours that can be detected and tracked with such technologies can be used to continuously evaluate and support students during their engagement with constructivist pedagogies. This paper focuses on students' CPS competence in practice-based learning (PBL) activities. More specifically, it presents an original framework to identify observable and objective differences in students CPS behaviours in open-ended, practice-based learning environments.

In order to make better sense of the results of this paper, it is important to make our understanding of CPS clear. Similar to the ideas of Panitz (1999), in this paper, the interpretation of collaboration is more of a philosophy of interaction, in which individual group participants' contribution is well respected and highlighted during the processes of problem-solving and knowledge construction. It is obvious to us that this approach differs from other group work approaches (including cooperation and peer tutoring) that are more formally structured to facilitate the creation of an end product or an aim. It is also different from competition-based approaches in which individuals aim to outperform their team mates. All these different approaches might be valuable to consider for teachers as part of a broad pedagogical repertoire in order to achieve different learning outcomes of various learning contexts.

The rest of the paper is structured as follows: in the next section, what we 
understand by CPS in the context of this research work is presented, how it can be observed is discussed and some key aspects of CPS to be investigated (namely, synchrony, individual accountability, equality and intra-individual variability) are defined. Section 3 is devoted to the methodology used in this research, including the participants, learning activities and instruments of measure used. Then the results are presented, which is followed by the discussion. The paper concludes with some conclusions and ideas for future research.

\section{About collaborative problem-solving}

CPS is a term that is increasingly used to refer to the process of a number of persons working together as equals to solve a problem. It brings together thinking and research about the separate topics of collaboration and problemsolving, both of which have a substantial research history in their own right. CPS is more than individual problem-solving in the company of others. It involves a set of sophisticated interaction skills that need to be utilised at the same time in service of supporting, directing, facilitating and coordinating the thinking of others with ones own, to achieve a mutually agreed goal. There is a substantial relevant research literature, going back some 50-60 years, across compulsory and post-compulsory education. This literature has used a range of different but overlapping terms including cooperative learning, collaborative learning, peer co-learning, peer tutoring, peer assisted learning as well as numerous other terms and phrases. Many authors have used these terms interchangeably, while others have tried to be quite distinct in how they define and describe them. Either way, it is very difficult to classify studies with respect to the different approaches referred to by this different terminology. However, it is worth discussing the constituent parts of CPS and ground it within the relevant wider literature concerning the associated concept of collaborative learning.

\subsection{A working definition of collaborative problem-solving}

At a basic level, the verb to collaborate means to work together, and thus it assumes cooperation because participants agree to work together and contribute to the interaction. Collaboration also assumes social coordination, because participants are sensitive and aware of the contribution made by others and the need to make their contributions pertinent and to coordinate their behaviour. But collaboration is more than this, it also involves participants 
working in unison as equals and oriented to a jointly agreed goal and often generating ideas that can form the basis for a possible solution or decision. Littleton and Mercer (2013) provide an eloquent account of collaborative learning that highlights some key features. These include that participants are engaged in a coordinated, continuing attempt to solve a problem or construct common knowledge; involved a coordinated joint commitment to a shared goal, reciprocity, mutuality, the continual (re-)negotiation of meaning. The participants are likely to experience a group sense or a feeling of shared endeavour; must establish and maintain inter-subjectivity or recognising that they have a shared understanding about their endeavour; must maintain a shared conception of the task or problem; must engage in interthinking: understanding each others plans and actions.

Regarding problem-solving on the other hand, OECD (2010) defines it as "an individuals capacity to engage in cognitive processing to understand and resolve problem situations where a method of solution is not immediately obvious. It includes the willingness to engage with such situations in order to achieve ones potential as a constructive and reflective citizen". A recent publication by Leadbeater (2016) sees problem-solving as a richer concept in which problem solvers: deploy knowledge in action, to work with others and to develop critical personal strengths such as persistence and resilience, to learn from feedback and overcome setbacks. This assumes collaboration as part of the problem-solving process, but helpfully also specifies the process as involving knowledge in action and overcoming setbacks. This resonates well with Marzano (1988), who has been highly influential on the OECDs definition and more widely in education. Marzano identified four knowledge utilisation processes: decision-making; problem-solving; experimental inquiry; and investigation.

Marzano described the process of problem-solving as happening when a learner attempts to accomplish a goal for which an obstacle exists (influenced by Rowe, 1985). Problem-solving requires the learner to use their existing relevant knowledge about the problem, retrieve prior knowledge, both about the subject matter of the problem and about the process of problem-solving, from memory that is relevant to the problem situation. The learner must identify the obstacle to problem solution, evaluate alternative goals and associated actions by processing information, select from these alternatives and put the selected goal oriented action into force.

As an overlap of these two key competencies from social and cognitive spaces, collaboration and problem-solving, the 2016 OECD PISA survey in- 
troduced the assessment of collaborative problem-solving (CPS) as part of their cycle of international assessments of 15-year-olds. Drawing most of the above considerations on collaboration and problem-solving, OECD defines CPS as "Collaborative problem-solving competency is the capacity of an individual to effectively engage in a process whereby two or more agents attempt to solve a problem by sharing the understanding and effort required to come to a solution and pooling their knowledge, skills and efforts to reach that solution" (OECD, 2015). However, even in their extensive and elaborate considerations on CPS, OECDs approach lacks to consider CPS as a multilevel process from different perspectives reflecting individuals, groups, and communities (Fiore et al., 2010a). Furthermore, due to their main interests, OECDs approach to CPS is an assessment approach rather than broader consideration of CPS as a tuition approach (Cukurova et al., 2016).

\subsection{Observing collaborative problem-solving behaviours}

As it must be clear by now from the conceptual considerations discussed earlier, CPS is a complex process that requires implementation of multiple social and cognitive competencies. This makes its observation, to see whether the CPS is of quality or not, extremely challenging for educational researchers and practitioners. In the learning sciences literature, there have been certain mechanisms suggested through which CPS may influence cognition and support deeper learning. These are relatively more observable features and therefore may be useful in developing ways to evaluate and support CPS. They include students demonstrating an ability to:

1. articulate, clarify and explain their thinking (Webb et al., 1995);

2. re-structure, clarify and in the process strengthen their own understanding and ideas to develop their awareness of what they know and what they do not know (Cooper, 1999; Howe et al., 1992);

3. adjust their explanations when presenting their thinking, which requires that they can also estimate others understandings (Baines \& Howe, 2010);

4. listen to ideas and explanations from others - this may lead listeners to develop understanding in areas that are missing from their own knowledge (Kutnick et al., 2005);

5. elaborate and internalise their new understanding as they process the ideas they hear about from others (Damon, 1984; Wertsch \& Stone, 1999); 
6. actively engage in the construction of ideas and thinking as part of the co-construction of understandings and solutions (Coleman, 1998; Hatano \& Inagaki, 1991; Hogan \& Tudge, 1999; Webb \& Palincsar, 1996);

7. resolve conflicts and respond to challenges by providing complex explanations, counter evidence and counter arguments (Baines et al., 2009; Howe \& Tolmie, 1998; Mercer, 1995);

8. search for new information to resolve the internal cognitive conflict that arises from discrepancies in the conceptual understanding of others (Doise \& Mugny, 1979; Howe, 2009).

9. Establishing and maintaining shared understanding; taking appropriate action to solve the problem; establishing and maintaining team organisation (OECD, 2015).

Looking at the suggested mechanisms from the learning sciences above, it becomes clear that all the mechanisms presented above require investigation of complex verbal interactions of students. Hence, it is not surprising to see that most research in educational technology aiming to investigate CPS focuses on investigating students' verbal input in digital learning environments, including chat boxes (Rouet, 2006), verbal interactions with on-line agents (Metcalf et al., 2011) and mobile tools that collect students' written reflections on their CPS practices (Lane et al., 2011). Nevertheless, such investigations are far from being straightforward. The investigation of complex CPS mechanisms through verbal indexes often require qualitative value judgments that are hard to validate, automate, and rely on. The verbal indexes are open to multiple interpretations regarding what mechanism or competence exactly do they belong to. Hence, they are also extremely hard to automate unless the potential interpretations are limited. Moreover, although verbal investigations are commonly conducted through sequencing of certain linear verbal actions, real-life CPS situations hardly fit in these linear sequences and occur often in more chaotic sequences. In addition, the transcription analysis of verbal indexes leads to losing important data of nonverbal actions and gestures. More recently, certain speech recognition technologies in verbal indexes are used to overcome some of those issues that relate to the use of verbal indexes in investigation of CPS in real-life environments, nevertheless they are not sensitive and accurate enough to be applicable in real classroom settings yet, particularly in dynamic and noisy classroom environments of PBL. It goes without saying that the oral 
language is a valuable source to investigate students learning mechanisms including CPS, however, it is argued here that nonverbal contributions are also valid and in some cases might even reflect more genuine observations of students intentions and ideas.

\subsection{Investigated aspects of collaborative problem-solving}

CPS has various aspects that need to be taken into account in discussions of the process. This paper focuses on four key aspects that are derived from learning sciences literature on collaboration and problem-solving. These are not the only aspects of CPS, however, they are important aspects of CPS and they have the potential to be interpreted through nonverbal indexes of students physical interactivity: synchrony, individual accountability, equality, and intra-individual variability. In this section, these concepts are briefly defined and how do they relate to CPS is explained.

\section{Synchrony}

The quality of the collaboration is related to the quality of the relationships of the students within the groups (Kreijns et al., 2003). This quality of the relationships is dependent on multiple aspects of group dynamics including reciprocality, impressions about others in the group, the feeling of being a community with other group members, and the perceptions about mutual dependency to achieve the aim (Kreijns et al., 2003). Some of these psychosocial processes of social interactions might be interpreted through observation of students' physical interactions. For instance, students who collaborate and get on well, show a high level of behavioural mirroring which then leads to high level of synchrony among group members (Vacharkulksemsuk \& Fredrickson, 2012). This synchrony, in turn, leads students to attributions of rapport and entitativity, which are significant indicators of high collaboration groups. As the previous research shows when people try to get along with another person, which is an important criterion for successful collaboration, they mimic the other person strongly (Chartrand \& Bargh, 1999). Similarly, in workplace and military environments, when groups are working well, they appear to converge their actions such that they move in unison (Lakens, 2010; Lakens \& Stel, 2011). In the educational technology research context, Schneider and Pea (2013) found that students' visual synchrony, measured with eye-trackers, positively correlated with students' learning gains. However, this finding was contradicted when it came to students' body synchronisation. Schneider and Blikstein (2015) found that even though gaze synchrony can be a strong predictor of student learning, body 
synchrony may not hold the same properties.

\section{Individual Accountability}

Individual accountability refers to students making sure that they undertake their share of the work and feel personally responsible for the groups success while others are also undertaking their share in completing the task. As argued by Slavin (1991) in his synthesis of research so far undertaken in the domain, group goals and individual accountability are the two key features of any successful group work. In groups that present high collaboration, students engage in promotive interaction and show a willingness to support each other in their joint efforts to complete the task and achieve the goal. Therefore there appear to be two main requirements of individual accountability 1) students' should undertake their share in completing the task, 2) each student's share is promoted and acknowledged by other members of the group. In an educational technology context, individual accountability is often considered to be measured with the amount of input generated by individual students. This satisfies the first requirement of individual accountability. However, also individual student's promotion and acknowledgement should be taken into account in considerations of individual accountability.

\section{Equality}

Equality is considered to be an important aspect of CPS by most educational researchers. For instance, early research by Damon and Phelps (1989) argue that equality and mutuality are two significant indexes student interaction that can be used to distinguish between high collaboration approaches from other types of peer learning including peer tutoring and jigsaw types of cooperative learning activities. Equality refers to a situation where participants are equal in status and participate in a two-way dialogue taking direction from one another, whilst mutuality refers to a situation where high mutuality means that discourse is extensive, intimate and connected. As argued by Damon and Phelps (1989) peer tutoring tends to foster dialogues that are relatively low on equality and varied in mutuality; cooperative learning foster ones that are relatively high in equality and low to moderate in mutuality; and collaboration fosters ones that are high in both. More recent researchers echo similar ideas. For instance, Dillenbourg, Lemaignan, Sangin, Nova, and Molinari (2016) use the concept of symmetry and argue that collaborative learning requires some sense of symmetry in terms of students' knowledge and skills as well as their contribution to interactions, and their status. 


\section{Intra-individual variability}

As emphasised by various other researchers CPS tends to be inherently interactive, interdependent, and dynamic (Blech \& Funke, 2005; Wirth \& Klieme, 2004). CPS can only occur if the students attempt to create a common ground about the problem/task they are dealing with (Clark, 1996). The establishment of such shared understanding occurs through students' communication and interaction with each other about the meaning of the problem/task. Creation of a common ground among group members is based on students' ability to understand behaviours, cognitions, and attitudes of other participants and oneselfs; and to translate this understanding into appropriate behaviour in social situations (Marlowe, 1986). In this dynamic context, the establishment of a common ground involves continuous correction of students' performance based on reactions of others during social exchanges (Argyle, 1979). This continuous correction and change in behaviours require a dynamic systems approach (Vallacher et al., 2002) to students' physical interactions, as dynamic systems approaches are ideally suited to describing the complex and constantly evolving patterns of students' actions (Magai \& Nusbaum, 1996). The dynamic system approaches are not new in educational research, however, their application requires an intensive and detailed observation of students interactions while they are solving problems collaboratively and, this is extremely challenging using the traditional educational research methods. Nevertheless, the emergence of the multimodal learning analytics research field provides various new methodologies and technologies to collect intensive, sequentially repeated measures of real-time data in reallife contexts. This paper takes advantage of such advancement in research methodologies and technologies, to investigate intra-individual variability aspect of CPS. Intra-individual data is derived from single individuals across multiple variables and multiple occasions and have been used in the past to make sense of numerous dynamic educational constructs including students cognitive changes (Metz, 1998; Schauble, 1996); their language development (Van Dijk \& Van Geert, 2007); social-emotional development (Lewis et al., 1999); and students self-regulatory behaviours (Mejía \& Hooker, 2013). In this research paper, the intra-individual variability of students physical interactivity is investigated as another potentially important aspect of CPS. To the best of our knowledge, such investigation has not been attempted before. 


\section{Methodology}

The overarching research aim of this study is to investigate the four aspects of CPS via nonverbal indexes of students' physical engagement. This aim was shaped into two main research questions:

- RQ1) What are the observable pattern differences between groups, in terms of their nonverbal indexes of physical interactivity related to the synchrony, equality, individual accountability, and intra-individual variability aspects of CPS?

- RQ2) What aspects of CPS represented with nonverbal indexes of physical interactivity in this research study, are good predictors of high CPS groups?

\subsection{Participants}

The participants were forty-five students, of which nine are in the first year of their secondary education (aged 11-12 years) from a girls-only secondary school in the UK, and the other thirty-six are Engineering students at a European University, with an average age of 20 years old, three female and thirty-three male. The study does not involve any primary school students in order to safely assume that all students have sufficient cognitive and social abilities for abstract thinking (Piaget, 1962) and perspective taking (Flavell, 1968). This research study employs a purposive sampling strategy. This is due to the explorative nature of the study. Participating high school students were recruited from a computer science class and selected by their teacher out of a class of thirty students based on their success in computer science. Engineering students were selected by their lecturers based on their success in programming courses. The teachers and the lecturers were asked to pick an even balance student ability as far as was possible, to ameliorate the bias of existing knowledge and skill differences between students on their CPS performances. The existing research shows that CPS to certain extent rely on domain knowledge (Mayer \& Wittrock, 1996; Funke \& Frensch, 2007). The aim, here, was to create groups that are symmetrical with respect to knowledge, status, and goals (Dillenbourg, 1999). However, there was no objective evaluation of student abilities for grouping purposes and this decision was left to the judgment of the classroom teachers and the lecturers of the students. This sampling strategy employed, as well as the practical challenges of receiving consent from student families led to an unbalanced 
number of samples for high school and university students. Written consent from students and their parents/guardians for high school students were collected, in line with the lead author's institutions ethics procedures.

\subsection{Learning Activities}

Next, the learning activities for high school and university students are described.

\section{Learning activity for high school students}

Students were set the task of building a working prototype using an Arduino-based physical computing kit, called TALKOO. The TALKOO kit comprises hardware modules, a visual IDE and prototyping material (Spikol et al., 2016). Sensor and actuator modules are pluggable, do not require soldering, and no prior knowledge in electronics is needed. The components have the ability to talk back to the visual IDE and to a learning analytics system. The students were also provided with craft materials (coloured paper, paper cups, wooden sticks, glitter, glue, etc.) with which to create their working prototypes in combination with the physical computing kit. The study involved two sessions that were run two days apart.

- Session 1 took place in the schools Information Technologies lab, during school hours, and involved the entire class of thirty students. The session lasted for 1 hour and 20 minutes, during which students worked with a TALKOO kit in pairs or groups of three. The purpose of Session 1 was for students to familiarise themselves with the physical computing kit through a number of predefined activities that exemplified the function of specific components (RGB light, temperature sensor and potentiometer) and logic functions (if statement, mapping function and switch function). A researcher, who was assisted by three colleagues and the class teacher, ran session 1.

- Session 2 took place at the university and involved nine students from the same class as Session 1. The participants were grouped into three groups of three students, and each group was identified with a different name. The students were grouped by their teachers based on their previous experiences. The session lasted about four hours and involved:

1. A refresher session, during which students worked through predefined activities that exemplified the functions of components and logic functions (as in Session 1) - 30 minutes 
2. An open-ended activity to build an interactive toy 2 hours

3. A brief activity to demonstrate the function of a motor 15 minutes

4. An open-ended activity to build an artefact using a motor 1 hour

Activities 1 and 3 were led by a researcher, who demonstrated how to connect and program the components. During activities 2 and 4 groups of students worked independently, but supported by an adult, who assisted them with troubleshooting the TALKOO kit and debugging the visual programming when/if needed. Only the data that is collected during the activities 2 and 4 is analysed in this research work.

\section{University Students' Learning Activity}

University students used exactly the same kit and the learning analytics system in their learning activities. However, due to the complexity of their programming and designs, they were allowed to work through the project system hardware, software and desk over 3 days, to complete 3 open-ended tasks.

Similar to the high school students, in an initial session, the university students were introduced to the system and the physical computing kit using a relatively simple introductory task. This is identical to the session 1 of the high school students, hence will not be repeated here. In the second session, students were asked to design and prototype an interactive toy (similarly to the task for the high school students). No specific instructions about the timing of these phases were given to students, and sessions lasted between 33 and 75 minutes (with the median of 63 minutes). The participants were grouped into twelve groups of three students, and each group worked on all three tasks and was identified with a different name.

\subsection{The NISPI framework for analysis}

This section presents the instruments of measurement and the research variables defined to formulate the NISPI framework.

NISPI - Nonverbal Indexes of $\underline{\text { Students } \underline{\text { Physical }} \text { Interactivity }}$

First, the coding scheme which is created in order to generate meaningful non-verbal indexes of students physical interactivity is described. The coding scheme makes use of three digits, 0, 1 and 2 to represent passive, semi-active and active student states. The active code (2) was used whenever a student's hand was active with an object; the semi-active code (1) was used when a student was not physically active, but their head was directed towards a peer (or the facilitator) who was active or to an object that was part of the 
learning task, and the passive code (0) was used in the rest of situations. students' behaviours were coded using thirty-second windows. Here, we use the expression "physically active" to refer to students' hands-on engagement with the practice-based learning activity.

There are two main features of the coding scheme. First, it is simple enough to be automated with existing learning analytics systems. Second, it is comprehensive enough for us to interpret the key aspects of CPS discussed earlier.

The video data analysed in this paper was collected with a multimodal learning analytics system (LAS). Complete description of the LAS system is out of the scope of this paper and details of its architecture can be seen here (Spikol et al., 2016). However, it is important to mention about the significant features of the LAS in order to provide better contextual understanding of this research. LAS collects multi-modal data from different sensors and input from the learners. The learning environment is designed to foster collaboration and includes an integrated screen and standing round table to allow learners to share and work together. The LAS collects data from both ambient (sensors) and live sources (human interaction). The ambient collection of data includes a computer vision system that uses color and depth cameras with audio (Microsoft Kinetic) for understanding how people interact around the workstation furniture.

To represent the groups, the following notation is used: the twelve university groups, with three students in each, have been named as Univ.n, where $n=A, . ., L$ while high school groups, with three students in each, have been named as Hsch.m, where $m=1,2,3$. Given a group $G$, its students are represented by G-s, where $s$ takes values 1,2 and 3 .

Let us define the interactivity index for a student $s_{i}$ in certain group $G$ as a variable $A I\left(s_{i}, t\right)$ that takes values $0,1,2$ and is given by:

$$
A I\left(s_{i}, t\right)=\text { Activity code of student } s_{i} \text { of group } G \text { at time } t
$$

where $\mathrm{i}=1,2,3$; and $\mathrm{t}=30,60, \ldots \ldots$

Given a group of students working together, the situation at any given moment is coded by concatenating the values of the activity codes for each student.

To exemplify this coding scheme, let us consider the situations pictured in Figures 1 and 2.

For the situation shown in Figure 1, it is coded as 2 (student on the left) 1 (student at the centre) and 1 (student on the right), i.e., 211. Similarly, the 


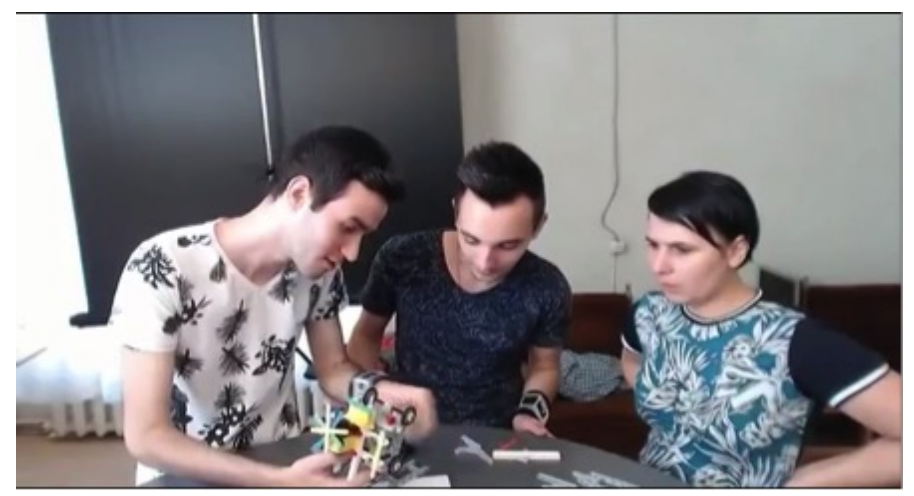

Figure 1: University students working on a project

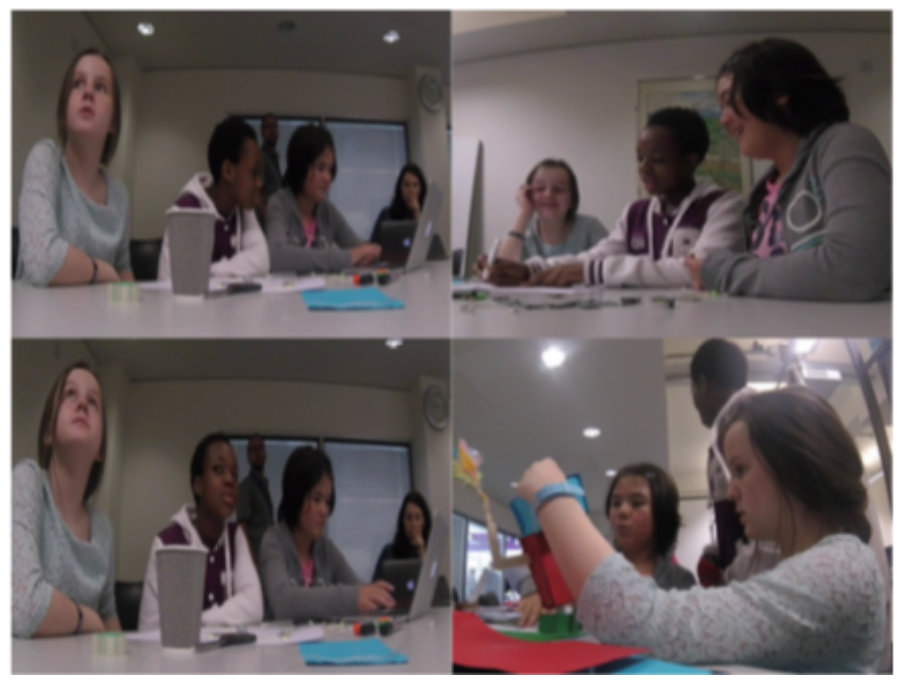

Figure 2: High school students working on a project

situations on Figure 2 would be coded as 012, 121, 002 and 202, respectively (from left to right and from up to down).

To validate the coding situations, two coders applied this coding scheme to all groups video data using 30-second windows. This procedure was used as a way of testing the reliability of the coding system generated. Whenever there was disagreement, the researchers discussed the data and revised their coding accordingly.

Using Nonverbal Indexes of students' Physical Interactivity to Interpret Key Aspects of CPS 
The use of active, semi-active and passive codes provides 27 potential positions in which three students working together could be at any particular point in time. These positions are categorised into groups of 10 situations and then identified potential representations of the key aspects of CPS discussed earlier (see table 1 below).

\begin{tabular}{ll}
\hline $\begin{array}{l}\text { Potential positions of three } \\
\text { students, CPS }\end{array}$ & $\begin{array}{l}\text { Categorised situations } \\
\text { three students }\end{array}$, CPS \\
\hline 000 & Only 0s (000) \\
$100,010,001$ & Two 0, one 1 (001) \\
$200,020,002$ & Two 0, one 2 (002) \\
$011,101,100$ & Two 1, one 0 (011) \\
$012,021,102,120,201,210$ & One of each $(012)$ \\
111 & Only 1s $(111)$ \\
$220,202,022$ & One 0, two 2s $(022)$ \\
$112,121,211$ & One two, two 1s $(211)$ \\
$122,212,221$ & One 1, two 2s $(221)$ \\
222 & Only 2s $(222)$ \\
\hline
\end{tabular}

Table 1: Positions, situations and predictors

Synchrony: The investigation of the concept of synchrony using students' nonverbal indexes of physical interactivity was the most straightforward one because the concept of synchrony dictates us to take into account three categories of situations: 000,111,222. In calculations of this paper, 222 is considered as a sign of active synchrony in which all three students are physically active. 111 was used to calculate the total amount of support the group received from a human resource outside the group (the teacher, the facilitator, another student from another group etc.). Finally, 000 indicates the total amount of time that students spent completely off the topic.

In particular, a research variable is defined to account for positive synchrony in each group. This variable is defined as:

$$
\operatorname{Syn}(G)=\text { percentage of } 222 \text { states in group } G
$$

Individual Accountability: As discussed earlier, the individual accountability of a group $G$ fundamentally depends on each students' undertaking their share in completing the task and the promotion and acknowledgement of each student's contribution to the workload. Here, whether 
each student contributes to their share of the workload is investigated as part of the equality concept through their mean values of physical interactivity scores. In order to interpret students' promotion and acknowledgment of each others contribution, the percentage of those situations in which at least one member student is purposefully observing the action taken by a member of the group are added $(221+211)$ and those situations in which at least one student is ignoring an action taken by a member of the group $(220,210,200)$ are subtracted. That is, the variable $I A(G)$ is defined as:

$$
I A(G)=\text { percentage of }(211,222) \text { - percentage of }(002,012,022)
$$

The hypothesis here, is that these moments might have the potential to reflect students individual accountability values, as they represent those moments in which an individual student's initiative to take action is valued and promoted by at least one other peer.

Equality: In order to investigate the extent to which the degree of equality observable in students' physical interactivity can be used as a nonverbal index to interpret CPS, the mean activity indexes of each group $A I(G-s, G, t)$ as defined below were investigated. The mean activity index of each student, the standard deviations, the average mean score and the total squared differences in the mean scores were considered. In particular, the formula used for the computation of the total square difference in a group G of students $s_{1}, s_{2}, s_{3}, T(G)$, is given by:

$$
T(G)=\sum_{t}\left[\left(A I_{\left(s_{1}, t\right)}-A I_{\left(s_{2}, t\right)}\right)^{2}+\left(A I_{\left(s_{1}, t\right)}-A I_{\left(s_{3}, t\right)}\right)^{2}+\left(A I_{\left(s_{2}, t\right)}-A I_{\left(s_{3}, t\right)}\right)^{2}\right]
$$

Intra-individual variability: The importance of creating a common ground in effective CPS process through dynamic communication and interaction, and the potential of intra-individual variability to measure such dynamic systems were discussed earlier in the paper. The hypothesis here is that during the course of practice-based learning activities, students' intraindividual variability of physical interactions may reflect the level of shared experience as a group. intra-individual variability refers to the amount of change in the behaviour of a student $s_{i}$ between two sequential time windows $t_{k}$ and $t_{k+1}$, and it is defined by:

$$
I V\left(s_{i}\right)=\frac{\left.\sum_{k=1}^{N-1} A I\left(s_{i}, t_{k}+1\right)-A I\left(s_{i}, t_{k}\right)\right)^{2}}{N-1}
$$




\section{Human Observer Analysis of Collaborative Problem-solving}

In order to create an independent variable to test the hypotheses presented above, human observers, who are experienced teachers, were asked to judge groups CPS using an analysis framework (Cukurova et al., 2016), based on OECDs assessment framework of CPS (OECD, 2015). The analysis framework has three key dimensions of collaboration (Establishing and maintaining shared understanding, Taking appropriate actions to solve the problem, Establishing and maintaining team organisation), and six key dimensions of problem-solving (Identifying facts, Representing and formulating knowledge, Generating hypotheses, Planning and executing, Identifying knowledge and skill deficiencies, Monitoring, reflecting and applying). Each group was observed with a human observer who watched students working on the learning activity and used a mobile tool to mark the critical incidents that relate to the key dimensions of collaboration and problem-solving as they occur. Based on their human judgment and teaching experience, human observers ranked groups as high, medium and low-level CPS groups. In order to ensure high agreement among observers, they are trained in a daylong, hands-on workshop about the CPS competencies and the CPS analysis framework. In this workshop, they were trained on the meaning of each competence and how they could potentially be judged in CPS. This ranking is used as an independent variable to shape the presentation of the results and arguments in this paper. Table 2 below shows the results of the human observers evaluation of groups CPS levels.

\begin{tabular}{llll}
\hline $\begin{array}{l}\text { High Competence } \\
\text { CPS Groups }\end{array}$ & $\begin{array}{l}\text { Med. Competence } \\
\text { CPS Groups }\end{array}$ & $\begin{array}{l}\text { Low CPS Groups } \\
\text { CPS }\end{array}$ \\
\hline Univ. D, Univ. F, & Univ. C, Univ. & E, Univ-B, Univ-K \\
Univ. J & Univ. G, Univ. H, & \\
& Univ. I, Univ. L & \\
Hsch X & - & & Hsch Y, Hsch Z \\
\hline
\end{tabular}

Table 2: Summary of human evaluations of students CPS competencies

Note that group Univ-A has not been classified in terms of the quality of their CPS. The reason is that the behaviour of the group was abnormal due to a technical problem with the visual programming tool of the group. The facilitator spent a lot of time to fix the visual programming tool of the group, while the group members were observing the facilitator. For the sake of data completeness, this group was not left out of the analysis for the different 
indicator values, but results of Univ. group A should be interpreted with caution.

\section{Results}

In this section, the observational pattern differences in the four key aspects related to CPS are presented, which are represented via indexes of students' physical interactivity.

\section{Synchrony:}

Table 3 below represents the percentages of different categories of situations. Synchrony states are labelled as (SYN), and the active synchrony state (222) and individual accountability states are (IndAccount), in bold. As explained before, individual accountability is computed by adding the percentages of situations in which at least one student actively observes a physically active student $(221,211)$ minus the percentages of situations in which at least one student does not actively observe a physically active student $(002,012,022)$. High CPS groups are shaded in dark grey, while low CPS groups are shaded light grey.

\begin{tabular}{|c|c|c|c|c|c|c|c|c|c|c|c|}
\hline & SYN 000 & SYN 111 & 001 & 002 & 011 & 012 & 022 & IA 211 & IA 221 & SYN 222 & Ind_Account \\
\hline Univ. A & $0,00 \%$ & $30,88 \%$ & $0,00 \%$ & $0,00 \%$ & $1,47 \%$ & $1,47 \%$ & $0,00 \%$ & $47,06 \%$ & $19,12 \%$ & $0,00 \%$ & $64,71 \%$ \\
\hline Univ. B & $4,55 \%$ & $0,00 \%$ & $0,00 \%$ & $16,36 \%$ & $0,00 \%$ & $10,91 \%$ & $8,18 \%$ & $23,64 \%$ & $26,36 \%$ & $10,00 \%$ & $14,55 \%$ \\
\hline Univ. C & $5,26 \%$ & $1,05 \%$ & $0,00 \%$ & $13,68 \%$ & $1,05 \%$ & $6,32 \%$ & $9,47 \%$ & $21,05 \%$ & $25,26 \%$ & $16,84 \%$ & $16,84 \%$ \\
\hline Univ. D & $0,00 \%$ & $7,14 \%$ & $0,00 \%$ & $0,00 \%$ & $0,00 \%$ & $1,95 \%$ & $5,19 \%$ & $18,18 \%$ & $29,22 \%$ & $38,31 \%$ & $40,26 \%$ \\
\hline Univ. E & $0,00 \%$ & $0,00 \%$ & $0,63 \%$ & $1,27 \%$ & $0,00 \%$ & $8,86 \%$ & $8,23 \%$ & $17,09 \%$ & $37,97 \%$ & $25,95 \%$ & $36,71 \%$ \\
\hline Univ. $\mathrm{F}$ & $0,00 \%$ & $0,65 \%$ & $0,00 \%$ & $0,00 \%$ & $0,00 \%$ & $0,00 \%$ & $3,90 \%$ & $13,64 \%$ & $33,12 \%$ & $48,70 \%$ & $42,86 \%$ \\
\hline Univ. G & $0,72 \%$ & $3,62 \%$ & $0,72 \%$ & $2,90 \%$ & $1,45 \%$ & $8,70 \%$ & $5,07 \%$ & $31,88 \%$ & $32,61 \%$ & $12,32 \%$ & $47,83 \%$ \\
\hline Univ. $\mathrm{H}$ & $6,40 \%$ & $0,00 \%$ & $0,00 \%$ & $12,00 \%$ & $0,00 \%$ & $11,20 \%$ & $11,20 \%$ & $8,00 \%$ & $26,40 \%$ & $24,80 \%$ & $0,00 \%$ \\
\hline Univ. I & $7,35 \%$ & $0,00 \%$ & $0,00 \%$ & $11,03 \%$ & $0,00 \%$ & $7,35 \%$ & $9,56 \%$ & $8,82 \%$ & $25,74 \%$ & $30,15 \%$ & $6,62 \%$ \\
\hline Univ. J & $0,00 \%$ & $2,97 \%$ & $0,00 \%$ & $0,00 \%$ & $0,00 \%$ & $0,00 \%$ & $0,00 \%$ & $12,87 \%$ & $40,59 \%$ & $43,56 \%$ & $53,47 \%$ \\
\hline Univ. $\mathrm{K}$ & $4,17 \%$ & $1,67 \%$ & $2,50 \%$ & $8,33 \%$ & $2,50 \%$ & $16,67 \%$ & $8,33 \%$ & $25,83 \%$ & $18,33 \%$ & $11,67 \%$ & $10,83 \%$ \\
\hline Univ. L & $0,94 \%$ & $0,00 \%$ & $0,00 \%$ & $3,77 \%$ & $0,94 \%$ & $8,49 \%$ & $7,55 \%$ & $28,30 \%$ & $25,47 \%$ & $24,53 \%$ & $33,96 \%$ \\
\hline HSch. X & $2,63 \%$ & $7,24 \%$ & $1,32 \%$ & $3,29 \%$ & $0,66 \%$ & $5,92 \%$ & $3,29 \%$ & $23,03 \%$ & $27,63 \%$ & $25,00 \%$ & $38,16 \%$ \\
\hline HSch. Y & $0,00 \%$ & $0,00 \%$ & $1,54 \%$ & $6,15 \%$ & $1,54 \%$ & $13,85 \%$ & $12,31 \%$ & $18,46 \%$ & $26,15 \%$ & $20,00 \%$ & $12,31 \%$ \\
\hline HSch. Z & $2,02 \%$ & $0,00 \%$ & $3,03 \%$ & $11,11 \%$ & $1,01 \%$ & $12,12 \%$ & $24,24 \%$ & $3,03 \%$ & $19,19 \%$ & $24,24 \%$ & $-25,25 \%$ \\
\hline
\end{tabular}

Table 3: Percentages of different situations for the total groups

The respective percentages of synchrony for university and high school students' groups present clear differences. The results show that, on average, high CPS university students' appear to spend relatively more time in active synchrony in comparison to high school students' groups. Perhaps more importantly, the results show that most groups spent very little time completely off-task in 000 synchrony. University groups Univ-B and Univ-I 
have the highest percentage of off-topic time spent among all groups. As the results of the SYN 111 show, most groups did not receive a whole group intervention from the teachers, lecturers, or facilitators. The notable exception here is that of group Univ-A. This group spent almost a third of their time receiving a group intervention from a facilitator $(30.88 \%)$, due to a technical problem with the visual programming tool. It is worth noting that all high school groups spent very little or no time observing a facilitators intervention.

If the results of those groups which were identified as high CPS groups by human observers are looked at (groups Univ-D, Univ-F, Univ-J and Hsch-X), it can clearly be seen that a pattern of high 222 percentages emerges. The three high CPS university groups have the highest three percentage values of active synchrony. On the other hand, those groups which were identified as low CPS by human observers appear to present much lower percentages of active synchrony. Looking at these results, the available evidence indicates that when the level of CPS increases, the amount of active synchrony increases in groups. That is worth further investigation at a larger scale to see how such results hold in big sample sizes. In other studies, results have shown that synchrony can be a good indicator of effective collaboration in some circumstances (such as students' gaze (Schneider \& Pea, 2013)) and it may not reflect collaboration in some others (such as body synchronisation (Schneider \& Blikstein, 2015)). The results of this paper, suggest that groups active synchrony data is a potential indicator of collaboration in problemsolving. The variances in results in the literature may be due to the type of synchrony as here we took active synchrony into account. Furthermore, other variables that differ in different studies in the literature such as the number of students in the groups studied or whether the students are in the same physical space or not can lead to different results.

Individual Accountability: As for individual accountability, table 3 shows some interesting results. The high CPS groups appear to have high percentages of individual accountability $(42.86 \%, 40.26 \%, 53.46 \%$ and $38.16 \%$ for groups Univ-F, Univ-D, Univ-J and Hsch-X, respectively), whereas low CPS groups appear to have low individual accountability values (for Univ$\mathrm{B}$ it is $11.49 \%$, for Univ-K is $10.53 \%$, and for Hsch-Z is $-25.25 \%$ ). However, there are also other data inputs that do not align with such observations. For instance, for groups Univ. A and Univ. G, even though were not considered as a high CPS group by human observers, their individual accountability value measured in calculations are quite high with the respective values of $64.71 \%$ and $47.83 \%$. These results may stem from various reasons. First of 
all, as we mentioned earlier group As results might be skewed due to the unusual level of facilitator support provided. Second, individual accountability as it was defined in this paper, might not reflect CPS. Third, the coding scheme and calculations can not capture the level of individual accountability in groups. Based on these results it is argued here that the concept of individual accountability and its measurement through nonverbal indexes of physical interactivity require further improvements to be effectively used in investigations of CPS.

$\boldsymbol{E}$ quality: Regarding the equality, first the extent to which the degree of equality observable in students' physical interactivity is investigated.

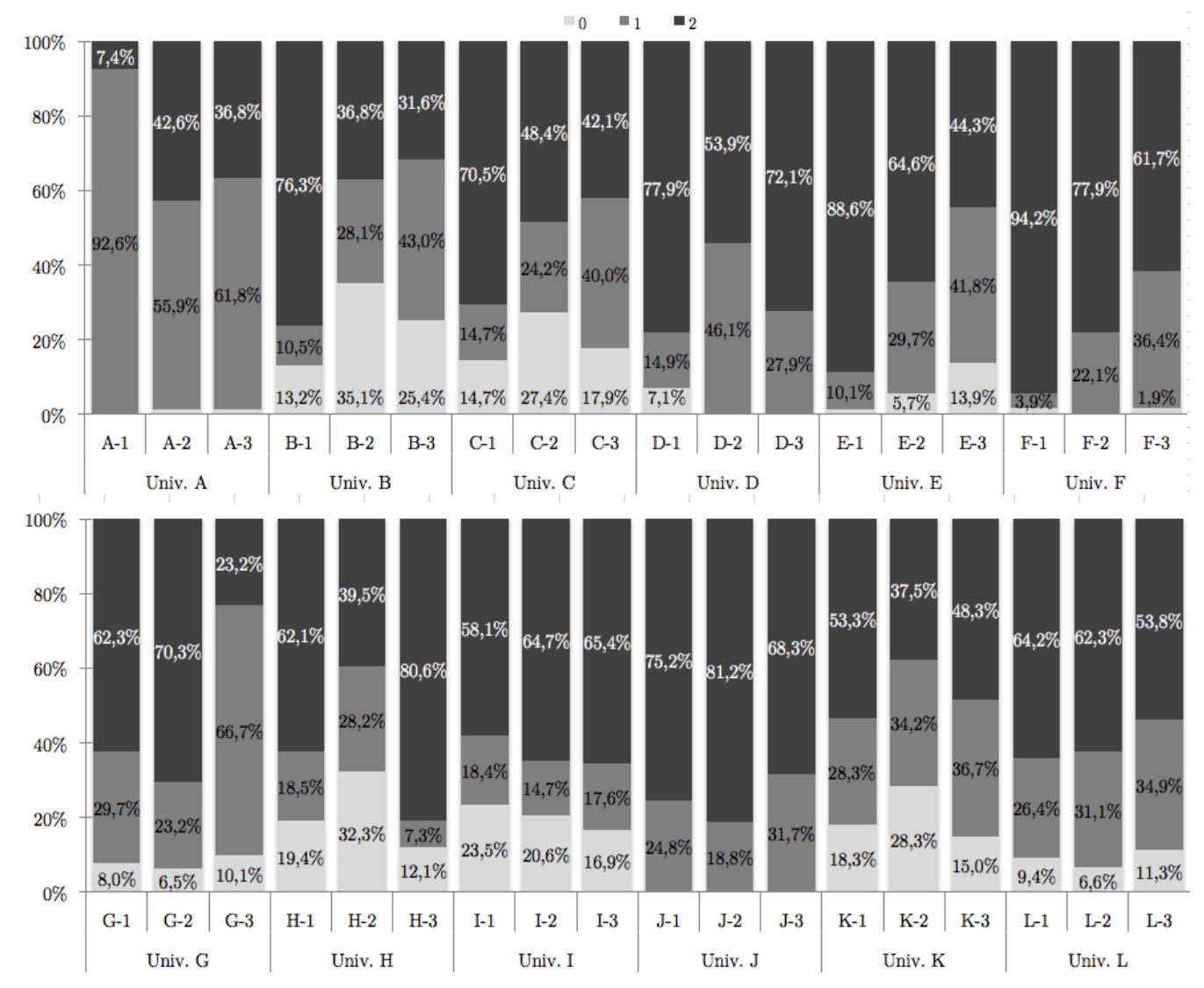

Figure 3: Percentages of individual student's number of passive 0, semi-active 1, and active codes 2 in university groups

Figures 3 and 4 illustrate that some groups showed more equality (e.g. 


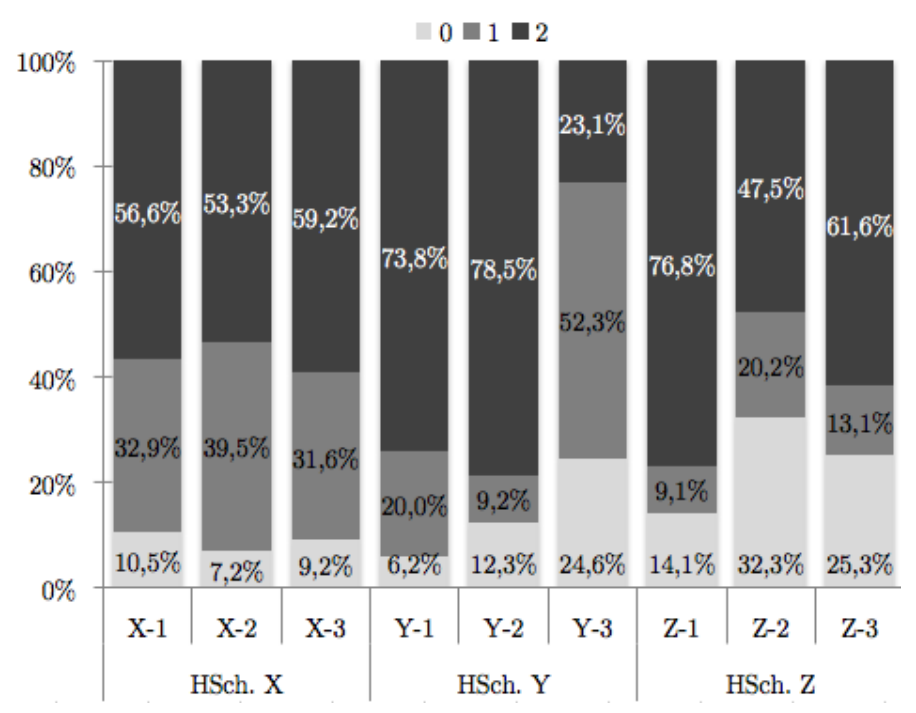

Figure 4: Percentages of individual student's number of passive 0 , semi-active 1 , and active codes 2 , in high school groups

Univ. I, Univ. J, Univ. D and Hsch. X) than others. It shows that the distribution is irregular for some groups (e.g. groups Univ. B, Univ. K, Univ. E) and identifies the students who were more physically active (e.g, student F-1 in Univ. F, or student Y-2 in HSch. Y) and students who were less physically active (e.g, student A-1 in Univ. A or student A-3 in Hsch.Y).

In order to have a better idea about the equality of students' physical interactivity, the mean scores of their codes were looked at. Table 2 presents these results and indicates in dark grey the groups which were identified by the observer as high CPS groups (U-Groups D, F and J and S-Group X). The groups identified as low CPS are indicated by a lighter shade of grey (U-groups B and K, S-groups Y and Z).

As the results above show, those groups coded as high CPS groups by human observers had higher mean scores for physical interactivity than those coded as low CPS groups. Considering the practice-based structure of the learning activity these results are not surprising. However, another finding that becomes clear from table 2 is that the groups rated as high CPS groups have member students whose physical interactivity mean scores are similar. By contrast, the groups rated as low CPS groups have member students whose mean scores for the physical interactivity of each student are more varied. For instance, in U-Group J, which was coded as a high CPS group, the 


\begin{tabular}{|c|c|c|c|c|c|c|c|c|c|c|c|c|c|c|c|c|c|c|}
\hline & \multicolumn{3}{|c|}{ Univ. A } & \multicolumn{3}{|c|}{ Univ. B } & \multicolumn{3}{|c|}{ Univ. C } & \multicolumn{3}{|c|}{ Univ. D } & \multicolumn{3}{|c|}{ Univ. U } & \multicolumn{3}{|c|}{ Univ. F } \\
\hline Student & A-1 & $\mathrm{A}-2$ & A-3 & B-1 & B-2 & B-3 & $\mathrm{C}-1$ & C-2 & $\mathrm{C}-3$ & D-1 & D-2 & D-3 & E-1 & E-2 & E-3 & F-1 & F-2 & F-3 \\
\hline Mean AI & 1,07 & 1,41 & 1,35 & 1,71 & 1,07 & 1,12 & 1,63 & 1,29 & 1,33 & 1,70 & 1,60 & 1,75 & 1,87 & 1,60 & 1,31 & 1,92 & 1,78 & 1,60 \\
\hline Sd AI & 0,26 & 0,53 & 0,51 & 1,71 & 1,07 & 1,12 & 0,64 & 0,78 & 0,65 & 0,61 & 0,49 & 0,43 & 0,37 & 0,59 & 0,70 & 0,33 & 0,42 & 0,53 \\
\hline Av. Mean & \multicolumn{3}{|c|}{1,28} & \multicolumn{3}{|c|}{1,30} & \multicolumn{3}{|c|}{1,41} & \multicolumn{3}{|c|}{1,68} & \multicolumn{3}{|c|}{1,59} & \multicolumn{3}{|c|}{1,77} \\
\hline $\mathrm{T}(\mathrm{G})$ & \multicolumn{3}{|c|}{0,20} & \multicolumn{3}{|c|}{0,76} & \multicolumn{3}{|c|}{0,21} & \multicolumn{3}{|c|}{0,04} & \multicolumn{3}{|c|}{0,47} & \multicolumn{3}{|c|}{0,16} \\
\hline & \multicolumn{3}{|c|}{ Univ. G } & \multicolumn{3}{|c|}{ Univ. H } & \multicolumn{3}{|c|}{ Univ. I } & \multicolumn{3}{|c|}{ Univ. J } & \multicolumn{3}{|c|}{ Univ. K } & \multicolumn{3}{|c|}{ Univ. L } \\
\hline Student & G-1 & G-2 & G-3 & $\mathrm{H}-1$ & $\mathrm{H}-2$ & H-3 & $\mathrm{I}-1$ & $\mathrm{I}-2$ & $\mathrm{I}-3$ & $\mathrm{~J}-1$ & $\mathrm{~J}-2$ & $\mathrm{~J}-3$ & $\mathrm{~K}-1$ & $\mathrm{~K}-2$ & $\mathrm{~K}-3$ & L-1 & L-2 & L-3 \\
\hline Mean AI & 1,54 & 1,64 & 1,13 & 1,45 & 1,10 & 1,71 & 1,43 & 1,55 & 1,58 & 1,75 & 1,81 & 1,68 & 1,35 & 1,09 & 1,33 & 1,55 & 1,56 & 1,42 \\
\hline Sd AI & 0,64 & 0,60 & 0,56 & 0,77 & 0,83 & 0,63 & 0,77 & 0,72 & 0,67 & 0,43 & 0,39 & 0,47 & 0,77 & 0,81 & 0,73 & 0,66 & 0,62 & 0,69 \\
\hline Av. Mean & \multicolumn{3}{|c|}{1,44} & \multicolumn{3}{|c|}{1,42} & \multicolumn{3}{|c|}{1,52} & \multicolumn{3}{|c|}{1,75} & \multicolumn{3}{|c|}{1,26} & \multicolumn{3}{|c|}{1,51} \\
\hline $\mathrm{T}(\mathrm{G})$ & \multicolumn{3}{|c|}{0,44} & & 0,57 & & & 0,04 & & & 0,02 & & & 0,13 & & & 0,03 & \\
\hline & & Sch. & & & Sch. & & & Sch. : & & & & & & & & & & \\
\hline Student & $\mathrm{X}-1$ & $\mathrm{X}-2$ & $\mathrm{X}-3$ & $\mathrm{Y}-1$ & $\mathrm{Y}-2$ & B-3 & $\mathrm{Y}-1$ & Y-2 & $\mathrm{Y}-3$ & & & & & & & & & \\
\hline Mean AI & 1,46 & 1,46 & 1,50 & 1,68 & 1,66 & 0,98 & 1,63 & 1,15 & 1,36 & & & & & & & & & \\
\hline Sd AI & 0,68 & 0,63 & 0,66 & 0,59 & 0,69 & 0,70 & 0,72 & 0,88 & 0,86 & & & & & & & & & \\
\hline Av. Mean & & 1,47 & & & 1,44 & & & 1,38 & & & & & & & & & & \\
\hline $\mathrm{T}(\mathrm{G})$ & & 0,00 & & & 0,94 & & & 0,34 & & & & & & & & & & \\
\hline
\end{tabular}

Table 4: Active mean scores, averages and total squared differences across groups

mean scores for the member students' physical interactivity were $1.75,1.81$, and 1.68; and the total squared differences the three students' physical interactivity scores was 0.02 . On the other hand, the mean physical interactivity scores for member students of U-Group B, which was coded as one of the low CPS groups, were 1.07,1.12, and 1.71, and the average of the differences between the three students' physical interactivity was 0.76 . The difference in physical interactivity scores for group B is approximately forty times bigger than the average differences in the high collaboration group J.

Also, triangle visualisations to represent this data can be used. The triangles shown in Figure 5 were drawn using the activity mean scores as the height values of $\mathrm{A}, \mathrm{B}$, and $\mathrm{C}$ points, for the students in groups Univ. D (high CPS) and Univ. K (low CPS), i.e. for the first triangle $h_{a}=1.70, h_{b}=1.60$, and $h_{c}=1.75$, and for the second triangle (U-group K) $h_{a}=1.35, h_{b}=1.09$, and $h_{c}=1.33$.

As can be seen, the triangle for the high CPS competence group (Univ. D) appears to be more equilateral than the one for the low CPS competence group (K). For instance, if $k$ value is calculated as the distance between the orthocentre and the barycentre, it can be seen that this distance is much larger for low CPS groups ( $k=0.13$ for Univ. D and $k=0.3$ for Univ. K). Such triangular visualisations can perhaps be used to present the performance of each group to students and teachers in CPS. Students can use them to 


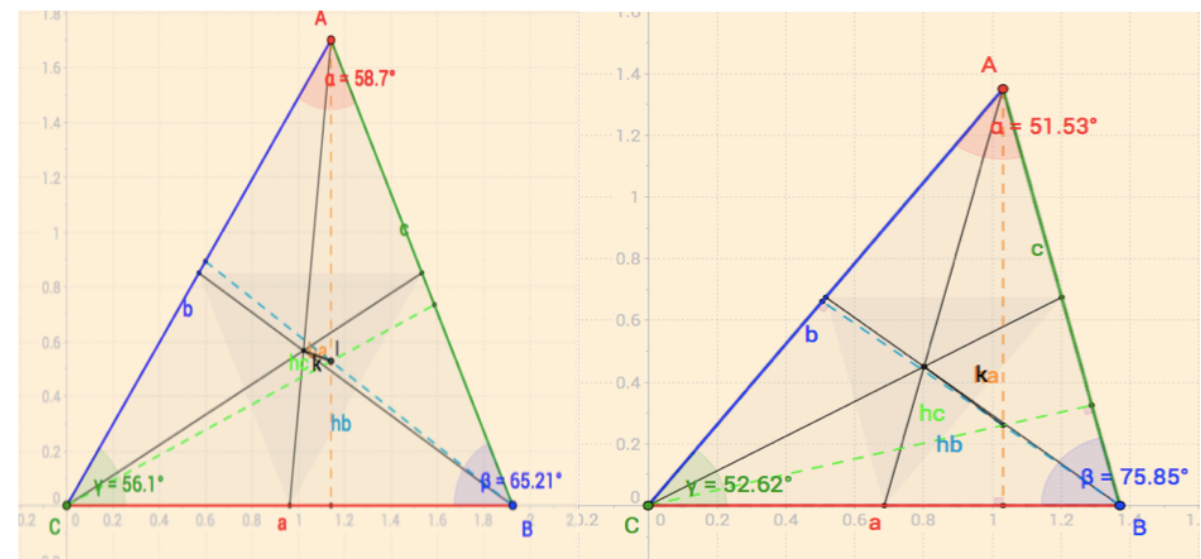

Figure 5: The visual representation of equality of students' physical interactivity (Group $\mathrm{D}$ is on the left and Group $\mathrm{K}$ is on the right)

reflect on their practice, and teachers can use them to shape and time their interventions. For instance, if such information is provided to teachers in real-time, they can prioritise their interventions to these groups that have the highest $k$ values. In addition to helping teachers time and prioritise their interventions, these visualisations may help them to shape their interventions. Teachers would scaffold groups so that the $\mathrm{k}$ distance would be shortened. For group Univ. $\mathrm{K}$ in fig 5 . the intervention would require the teacher to stimulate student 2 to be more engaged in the learning activity.

Intra-individual variability: As discussed earlier, here, the mean squared differences is considered as a good method to calculate students' intra-individual variability (IV), as it represents the mean value of the total amount of changes in student's physical interactivity.

The table 5 below shows the intra-individual variability and total squared differences values for university and high school groups. Results show that high CPS groups show lower IV values, whereas low CPS groups show higher IV values. If the total squared differences of individual students' IV scores in groups are looked at, high CPS groups appear to have low values (Univ. $\mathrm{D}=0.00$, Univ. $\mathrm{F}=0.05$, Univ. $\mathrm{J}=0.01$, Hsch. $\mathrm{X}=0.06$ ), whereas low collaboration groups have the highest two figures (Univ. $\mathrm{B}=0.16$, Univ. $\mathrm{K}=0.55$, HSch. $\mathrm{Z}=1.49$ ). The low IV values can be achieved if students continue their level of physical interactivity for longer periods of times, rather than having frequent changes in their interactivity. Figure 6 illustrates the 


\begin{tabular}{|c|c|c|c|c|c|c|c|c|c|c|c|c|c|c|c|c|c|c|}
\hline \multirow[b]{2}{*}{ Student } & \multicolumn{3}{|c|}{ Univ. A } & \multicolumn{3}{|c|}{ Univ. B } & \multicolumn{3}{|c|}{ Univ. C } & \multicolumn{3}{|c|}{ Univ. D } & \multicolumn{3}{|c|}{ Univ. U } & \multicolumn{3}{|c|}{ Univ. F } \\
\hline & A-1 & A-2 & A-3 & B-1 & B-2 & B-3 & $\mathrm{C}-1$ & $\mathrm{C}-2$ & $\mathrm{C}-3$ & D-1 & D-2 & D-3 & E-1 & $\mathrm{E}-2$ & E-3 & F-1 & F-2 & F-3 \\
\hline IV & 0,54 & 0,61 & 0,83 & 0,52 & 0,61 & 0,84 & 0,68 & 0,89 & 0,51 & 0,29 & 0,27 & 0,24 & 0,27 & 0,53 & 0,42 & 0,20 & 0,25 & 0,38 \\
\hline Total sq diff & \multicolumn{3}{|c|}{0,14} & \multicolumn{3}{|c|}{0,16} & \multicolumn{3}{|c|}{0,22} & \multicolumn{3}{|c|}{0,00} & \multicolumn{3}{|c|}{0,10} & \multicolumn{3}{|c|}{0,05} \\
\hline & \multicolumn{3}{|c|}{ Univ. G } & \multicolumn{3}{|c|}{ Univ. H } & \multicolumn{3}{|c|}{ Univ. I } & \multicolumn{3}{|c|}{ Univ. J } & \multicolumn{3}{|c|}{ Univ. K } & \multicolumn{3}{|c|}{ Univ. L } \\
\hline Student & G-1 & G-2 & G-3 & $\mathrm{H}-1$ & $\mathrm{H}-2$ & H-3 & $\mathrm{I}-1$ & $\mathrm{I}-2$ & $\mathrm{I}-3$ & $\mathrm{~J}-1$ & \begin{tabular}{|l|}
$\mathrm{J}-2$ \\
\end{tabular} & $\mathrm{~J}-3$ & $\mathrm{~K}-1$ & $\mathrm{~K}-2$ & K-3 & $\mathrm{L}-1$ & L-2 & L-3 \\
\hline IV & 0,60 & 0,41 & 0,63 & 0,73 & 0,79 & 0,46 & 0,77 & 0,58 & 0,72 & 0,22 & 0,22 & 0,27 & 0,98 & 0,92 & 0,43 & 0,82 & 0,60 & 0,54 \\
\hline Total sq diff & \multicolumn{3}{|c|}{0,08} & \multicolumn{3}{|c|}{0,19} & \multicolumn{3}{|c|}{0,06} & \multicolumn{3}{|c|}{0,01} & \multicolumn{3}{|c|}{0,55} & \multicolumn{3}{|c|}{0,13} \\
\hline & \multicolumn{3}{|c|}{ HSch. X } & \multicolumn{3}{|c|}{ HSch. Y } & \multicolumn{3}{|c|}{ HSch. Z } & & & & & & & & & \\
\hline Student & $\mathrm{X}-1$ & $\mathrm{X}-2$ & $\mathrm{X}-3$ & $\mathrm{Y}-1$ & $\mathrm{Y}-2$ & Y-3 & $\mathrm{Z}-1$ & $\mathrm{Z}-2$ & $\mathrm{Z}-3$ & & & & & & & & & \\
\hline IV & 0,74 & 0,57 & 0,73 & 0,67 & 0,84 & 0,83 & 0,84 & 1,18 & 1,49 & & & & & & & & & \\
\hline Total sq diff & \multicolumn{3}{|c|}{0,06} & \multicolumn{3}{|c|}{0,05} & \multicolumn{3}{|c|}{0,64} & & & & & & & & & \\
\hline
\end{tabular}

Table 5: IV scores and total squared differences in IV of groups

chronological changes in IV values for groups Univ. F and Hsch. X (high CPS) and Univ.K (low CPS).

As the chronological changes of IV values show, high CPS groups appear to have been changing in unison, whereas low CPS groups show varied changes for individual students. Such unison in the chronological investigation can only be achieved if students were continuing their actions for longer periods and having a similar frequency of changes. Perhaps, one potential explanation for continuing on the same action is that these students have a better mutual understanding of the task/problem they are working on. When such mutual understanding does not occur among group members, their actions may vary more often as they stop and start their physical activities more frequently. The importance of mutual understanding as an important dimension of collaboration has been recognised by other researchers (Andriessen et al., 2013; Barkley et al., 2014; Engestrom, 2014). The results suggest that the intra-individual variability of students' physical interactivity can be a potential indicator of CPS quality in practice-based learning activities.

\section{Discussion}

In this paper, the potential of four constructs, interpreted via nonverbal indexes of students' physical interactivity, to identify students' level of CPS is presented. CPS can be investigated at the individual, group, or organisational level (Fiore et al., 2010b). With the intention of creating a holistic understanding of CPS, both individual and the group levels were considered here. The synchrony and individual accountability constructs through stu- 

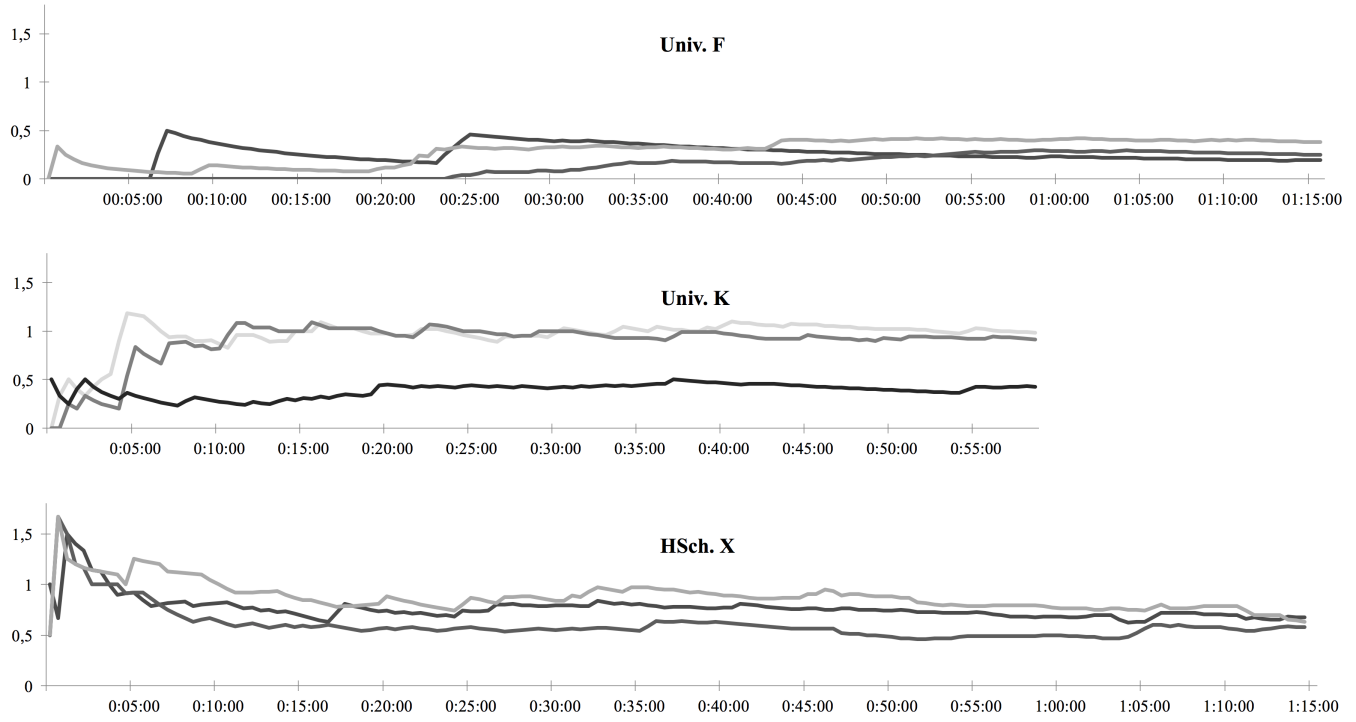

一 Student 1 -Student 2 -Student 3

Figure 6: Chronological changes in IV values of selected groups

dents' codes were discussed and interpreted at the whole group level, and the equality and the intra-individual variability values were discussed and interpreted through individual students mean values. The sample involves data from both high school and university students, however does not focus on investigating the differences between different educational levels. The comparison is at the level of students' CPS competences (comparing at high competence CPS groups' behaviours with low competence CPS groups' behavirous) in two different contexts of secondary and tertiary education.

The first research question was: What are the observable pattern differences between groups, in terms of their nonverbal indexes of physical interactivity related to the synchrony, equality, individual accountability, and shared understanding aspects of CPS? In this vein, the results show that students in high CPS groups (as evaluated by expert teachers) have member students who have high and equal scores for physical interactivity and low and equal scores for intra-individual variability. Moreover, high competence CPS groups appear to have high levels of student synchrony and individual accountability values. Related to the first research question, the second research question was: What aspects of CPS represented with nonverbal in- 
dexes of physical interactivity in this research study, are good predictors of high CPS groups? The results show that the concepts of synchrony, equality and intra-individual variability are good predictors of CPS competence of students. However, individual accountability, when measured with the coding scheme on its own in practice-based learning environments, appears to be less valuable to predict the quality of CPS.

The results presented in this paper are aligned with the existing research findings in the field. For instance, earlier research on peer learning shows that collaborative groups are high in equality and mutuality (Damon \& Phelps, 1989), students move in unison (Lakens, 2010; Lakens \& Stel, 2011), they are synchronised in their gaze during collaboration (Schneider \& Pea, 2013), they present symmetry in terms of their status and contributions (Dillenbourg et al., 2011), they present increased peers' turn-taking and balanced contributions (Dias et al., 2017). The paper expands the knowledge in the learning sciences field by introducing a new methodology to interpret the key concepts of equality, individual accountability and synchrony as well as bringing in the concept of intra-individual variability as a potential indicator of the quality of CPS competence in practice-based learning activities.

The effective implementation and evaluation of CPS depend on identification of the observable features and processes of CPS. As it is presented in this paper, some of these can be detected via indexes of students' physical interactions. Nonverbal indexes are particularly useful for detecting students' mental states in dynamic learning environments like practice-based learning. This argument is well supported by research in social cognition which establishes that the body movements might provide an immediate understanding of mental states and intentions of students (Fuchs \& De Jaegher, 2009; Gallese, 2007). This research stream presents evidence that bodily states including postures, gaze, movement etc. are core to social cognition and can be used to interpret mental states (Barsalou et al., 2003). Here, the concepts of synchrony, individual accountability, equality, and intra-individual variability in are investigated and shown to be identified from students' nonverbal behaviours in practice-based learning environments.

The observable features of CPS presented here, have significant implications for design, research and development of technology in education. The findings have immediate pedagogical implications such as increasing teachers awareness of the concepts of equality, synchrony, individual accountability and intra-individual variability as well as how do they relate to students CPS competence when technology is utilised in education. Moreover, the findings 
inform the design of multimodal learning analytics and artificial intelligence in education technologies to support students' CPS competence based on their observable behaviour data. Recently, observable features of learning processes are used to engineer feature vectors of behaviour data as well as training algorithms to cluster and classify student competence (see for instance blinded for review). These technologies can track student behaviours from multimodal data (computer vision systems, hand tracking, face tracking, gaze direction etc.) to help teachers identify students who need support and prioritise their interventions. They are also beneficial for students, particularly for those who are clustered as low competence CPS, to reflect on their own behaviours to improve their CPS competences through reflection.

Lastly, the limitations of this work should be pointed out in addition to its potential benefits. The evaluation of student performance through concepts such as synchrony, individual accountability, equality and intra-individual variability is only one part of understanding how good a student (or a group of students) is at CPS. The CPS process is much more complicated than any of the existing statistical measures of CPS performance, particularly when it comes to complex learning environments of practice-based learning. However, these statistical measurements act as useful indicators of potential quality of CPS and their visualisations can be used to provide valuable feedback to teachers to adapt their interventions in classrooms. It is argued here that the value and accuracy of such measurements increase when they are considered together with teachers professional judgment, rather than independently. Finally, although the results are derived from a relatively small sample, the analysis is based on a detailed investigation of data which involves different contexts of secondary and tertiary level education. The immediate future work will be directed towards further investigation of the validity and automation of this approach with larger sample sizes.

\section{Conclusions}

This research paper presents four nonverbal indexes of students' physical interactivity that can be used to interpret the quality of CPS competence in practice-based activities. Results have shown that students in high competence CPS groups show high levels of physical interactivity and low levels of intra-individual variability. Both of these indexes present smaller ranges in high competence CPS groups when compared with low competence CPS 
groups. Moreover, high competence CPS groups appear to present high levels of synchrony values compared to low competence CPS groups.

The NISPI framework is a practical and valuable approach that can inform the research, design, and implementation of technology in education. It is envisaged that the future research will involve attempts to automate this process of interpreting student behaviours in order to provide real-time feedback to students and teachers about the CPS competences of students. Students need appropriate support and guidance to improve their knowledge and key skills including CPS (Cukurova \& Bennett, 2017) and the results of this paper can be harnessed to provide this support and guidance.

CPS competence is needed to prepare students for the future of democratic societies in which humans mostly deal with ill-defined, open-ended tasks whereas the most well-defined tasks are dealt with automated agents. Education has utmost significance to provide the required training of students in CPS. This paper is a contribution to this big picture with some statistical analysis of students' nonverbal indexes of their physical interactivity. However, it is worth noting that the most effective and efficient education can only be provided through combining such measurements of student performances with teachers expert instinctive judgment of the learning situations. Nevertheless, it would be a mistake to rely only on instinctive judgment, in the same way, that it would be a mistake to rely only on statistical calculations of certain proxies of complex learning processes. The measures proposed here are aimed to empower teachers with information that they can use to obtain a better view of the whole picture so that they can plan and adapt instruction accordingly.

\section{Acknowledgments}

This work is co-funded by the European Union under the PELARS project (GA No. 619738). We would like to particularly thank Daniel Spikol and Emanuele Ruffaldi. The third author was partially supported by Agencia Estatal de Investigación (AEI) y el Fondo Europeo de Desarrollo Regional (FEDER), TIN2016-80774-R.

\section{References}

Andriessen, J., Baker, M., \& Suthers, D. (2013). Arguing to learn: Confronting cognitions in computer-supported collaborative learning environments volume 1. Springer Science \& Business Media. 
Argyle, M. (1979). New developments in the analysis of social skills. In A. Wolfgang (Ed.), Non-verbal behaviour: Application and cultural implications (pp. 139-158). New York: Academic Press.

Baines, E., \& Howe, C. (2010). Discourse topic management and discussion skills in middle childhood: The effects of age and task. First Language, 30, 508-534.

Baines, E., RubieDavies, C., \& Blatchford, P. (2009). Improving pupil group work interaction and dialogue in primary classrooms: results from a yearlong intervention study. Cambridge Journal of Education, 39, 95-117.

Barkley, E. F., Cross, K. P., \& Major, C. H. (2014). Collaborative learning techniques: A handbook for college faculty. John Wiley \& Sons.

Barron, B., \& Darling-Hammond, L. (2010). Prospects and challenges for inquiry-based approaches to learning. The nature of learning: Using research to inspire practice, (pp. 199-225).

Barsalou, L. W., Niedenthal, P. M., Barbey, A. K., \& Ruppert, J. A. (2003). Social embodiment. Psychology of learning and motivation, 43, 43-92.

Blech, C., \& Funke, J. (2005). Dynamis review: An overview about applications of the dynamis approach in cognitive psychology. Bonn: German Institute for Adult Education (DIE), (pp. 1-47).

Blikstein, P., \& Worsley, M. (2016). Multimodal learning analytics and education data mining: Using computational technologies to measure complex learning tasks. Journal of Learning Analytics, 3, 220-238.

Chartrand, T. L., \& Bargh, J. A. (1999). The chameleon effect: the perception-behavior link and social interaction. Journal of personality and social psychology, $76,893$.

Clark, R. E. (1996). Using language. Cambridge: Cambridge University Press.

Coleman, E. B. (1998). Using explanatory knowledge during collaborative problem solving in science. Journal of the Learning Sciences, 7, 387-427. 
Cooper, M. (1999). Classroom choices from a cognitive perspective on peer learning. In A. M. O'Donnell, \& A. King (Eds.), Cognitive perspectives on peer learning (pp. 215-234). Hillsdale, NJ: Erlbaum.

Cukurova, M., Avramides, K., Spikol, D., Luckin, R., \& Mavrikis, M. (2016). An analysis framework for collaborative problem solving in practice-based learning activities: a mixed-method approach. In Proceedings of the International Conference on Learning Analytics and Knowledge (pp. 84-88). Edinburgh, United Kingdom: ACM.

Cukurova, M., \& Bennett, J. (2017). Students knowledge acquisition and ability to apply knowledge into different science contexts in two different independent learning settings. Research in Science and Technology Education, (pp. 1-18).

Damon, W. (1984). Peer education: The untapped potential. Journal of Applied Developmental Psychology, 5, 331-343.

Damon, W., \& Phelps, E. (1989). Critical distinctions among three approaches to peer education. International Journal of Educational Research, 13, 9-19.

Dias, B., Hadjileontiadou, S., Diniz, J., \& Hadjileontiadis, L. (2017). Computer-based concept mapping combined with learning management system use: An explorative study under the self- and collaborative-mode. Computers and Education, 10\%, 127-146.

Dillenbourg, P. (1999). What do you mean by 'collaborative learning'? Cognitive and Computational Approaches, (pp. 1-19).

Dillenbourg, P., Lemaignan, S., Sangin, M., Nova, N., \& Molinari, G. (2016). The symmetry of partner modelling. International Journal of ComputerSupported Collaborative Learning, 11, 227-253.

Dillenbourg, P., Zufferey, G., Alavi, H., Jermann, P., Do-Lenh, S., \& Bonnard, Q. (2011). Classroom orchestration: The third circle of usability. In International Conference on Computer Supported Collaborative Learning 2011 (pp. 510-517). ISLS. 
Doise, W., \& Mugny, G. (1979). Individual and collective conflicts of centrations in cognitive development. European Journal of Social Psychology, 9, 105-108.

Engestrom, Y. (2014). Learning by expanding. Cambridge University Press.

Fiore, S. M., Rosen, M. A., Smith-Jentsch, K., Salas, E., Letsky, M., \& Warner, N. (2010a). Toward an understanding of macrocognition in teams: predicting processes in complex collaborative contexts. Human Factors: The Journal of the Human Factors and Ergonomics Society, .

Fiore, S. M., Rosen, M. A., Smith-Jentsch, K., Salas, E., Letsky, M., \& Warner, N. (2010b). Toward an understanding of macrocognition in teams: Predicting processes in complex collaborative contexts. Human Factors: The Journal of the Human Factors and Ergonomics Society, .

Flavell, J. H. (1968). The development of role-taking and communication skills in children. New York: National Inst. of Mental Health.

Fuchs, T., \& De Jaegher, H. (2009). Enactive intersubjectivity: Participatory sense-making and mutual incorporation. Phenomenology and the Cognitive Sciences, 8, 465-486.

Funke, J., \& Frensch, P. A. (2007). Complex problem solving: the European perspective. New York: Psychology Press.

Gallese, V. (2007). Before and below 'theory of mind': embodied simulation and the neural correlates of social cognition. Philosophical Transactions of the Royal Society of London B: Biological Sciences, 362, 659-669.

Hatano, G., \& Inagaki, K. (1991). Sharing cognition through collective comprehension activity. Perspectives on socially shared cognition, (pp. 331$348)$.

Hogan, D. M., \& Tudge, J. R. (1999). Implications of vygotsky's theory for peer learning. Cognitive perspectives on peer learning, (pp. 39-65).

Howe, C. (2009). Collaborative group work in middle childhood. Human Development, 52, 215-239. 
Howe, C., \& Tolmie, A. (1998). Computer support for learning in collaborative contexts: prompted hypothesis testing in physics. Computers and Education, 30, 223-235.

Howe, C., Tolmie, A., Anderson, A., \& Mackenzie, M. (1992). Conceptual knowledge in physics: The role of group interaction in computer-supported teaching. Learning and Instruction, 2, 161-183.

Kirschner, P. A., Sweller, J., \& Clark, R. E. (2006). Why minimal guidance during instruction does not work: An analysis of the failure of constructivist, discovery, problem-based, experiential, and inquiry-based teaching. Educational Psychologist, 41, 75-86.

Klahr, D., \& Nigam, M. (2004). The equivalence of learning paths in early science instruction: Effects of direct instruction and discovery learning. Psychological Science, 15, 861-887.

Kreijns, K., Kirschner, P. A., \& Jochems, W. (2003). Identifying the pitfalls for social interaction in computer-supported collaborative learning environments: a review of the research. Computers in Human Behavior, 19, $335-353$.

Kutnick, P., Blatchford, P., \& Baines, E. (2005). Grouping of pupils in secondary school classrooms: possible links between pedagogy and learning. Social psychology of education, 8, 349-374.

Lakens, D. (2010). Movement synchrony and perceived entitativity. Journal of Experimental Social Psychology, 46, 701-708.

Lakens, D., \& Stel, M. (2011). If they move in sync, they must feel in sync: Movement synchrony leads to attributions of rapport and entitativity. Social Cognition, 29, 1.

Lane, H. C., Noren, D., Auerbach, D., Birch, M., \& Swartout, W. (2011). Intelligent tutoring goes to the museum in the big city: A pedagogical agent for informal science education. In International Conference on Artificial Intelligence in Education (pp. 155-162). Springer.

Leadbeater, C. (2016). The Problem Solvers: The teachers, the students and the radically disruptive nuns who are leading a global learning movement. London: Pearson. 
Lewis, M. D., Lamey, A. V., \& Douglas, L. (1999). A new dynamic systems method for the analysis of early socioemotional development. Developmental Science, 2, 457-475.

Littleton, K., \& Mercer, N. (2013). Interthinking: Putting Talk to Work. Abingdon, Oxon.: Routledge.

Magai, C., \& Nusbaum, B. (1996). Personality change in adulthood. Handbook of emotion, adult development, and aging, (pp. 403-420).

Marlowe, H. A. (1986). Social intelligence: Evidence for multidimensionality and construct independence. Journal of educational psychology, 78, 52.

Marzano, R. J. (1988). Dimensions of thinking: A framework for curriculum and instruction. ERIC.

Mayer, R. E. (2004). Should there be a three-strikes rule against pure discovery learning? the case for guided methods of instruction. American Psychologist, 59, 14-19.

Mayer, R. E., \& Wittrock, M. C. (1996). Problem-solving transfer. Handbook of educational psychology, (pp. 47-62).

Mejía, S. T., \& Hooker, K. (2013). Social regulatory processes in later life: A web-based microlongitudinal study. Psychology and aging, 28, 864.

Mercer, N. (1995). The guided construction of knowledge: Talk amongst teachers and learners. Multilingual matters.

Metcalf, S., Kamarainen, A., Tutwiler, M. S., Grotzer, T., \& Dede, C. (2011). Ecosystem science learning via multi-user virtual environments. International Journal of Gaming and Computer-Mediated Simulations (IJGCMS), 3, 86-90.

Metz, K. E. (1998). Emergent understanding and attribution of randomness: Comparative analysis of the reasoning of primary grade children and undergraduates. Cognition and Instruction, 16, 285-265.

Montessori, M. (1965). Spontaneous Activity in Education. London: Benediction Classics. 
OECD (2010). PISA 2012 field trial problem solving framework - Draft subject to possible revision after the field trial. Paris: OECD Publications.

OECD (2015). Draft Collaborative Problem Solving Framework. Report.

Panitz, T. (1999). Collaborative versus Cooperative Learning: A Comparison of the Two Concepts Which Will Help Us Understand the Underlying Nature of Interactive Learning. ERIC.

Piaget, J. (1962). The role of imitation in the formation of representations (h. wallon). L'Evolution Psychiatrique, 27, 141-150.

Rouet, J.-F. (2006). The skills of document use. Mahwah, NJ: Erlbaum.

Rowe, H. (1985). Problem solving and intelligence. Hillsdale, NJ: Erlbaum.

Schauble, L. (1996). The development of scientific reasoning in knowledgerich contexts. Developmental Psychology, 32, 102.

Schneider, B., \& Blikstein, P. (2015). Unraveling students' interaction around a tangible interface using multimodal learning analytics. Journal of Educational Data Mining, 7 .

Schneider, B., \& Pea, R. (2013). Real-time mutual gaze perception enhances collaborative learning and collaboration quality. International Journal of Computer-Supported Collaborative Learning, 8, 375-397.

Slavin, R. E. (1991). Synthesis of research of cooperative learning. Educational leadership, 48, 71-82.

Spikol, D., Avramides, K., Cukurova, M., Vogel, B., Luckin, R., Mavrikis, M., \& Ruffaldi, E. (2016). Exploring the interplay between human and machine annotated multimodal learning analytics in hands-on stem activities. Proceedings of the 6th International Learning Analytics $\&$ Knowledge Conference, (pp. 522-523).

Vacharkulksemsuk, T., \& Fredrickson, B. L. (2012). Strangers in sync: Achieving embodied rapport through shared movements. Journal of experimental social psychology, 48, 399-402. 
Vallacher, R. R., Read, S. J., \& Nowak, A. (2002). The dynamical perspective in personality and social psychology. Personality and Social Psychology Review, 6, 264-273.

Van Dijk, M., \& Van Geert, P. (2007). Wobbles, humps and sudden jumps: A case study of continuity, discontinuity and variability in early language development. Infant and Child Development, 16, 7-33.

Webb, N., \& Palincsar, A. (1996). Group processes in the classroom. In D. C. Berliner, \& R. C. Calfee (Eds.), Handbook of educational psychology (pp. 841-873). New York: Macmillan.

Webb, N., Troper, J. D., \& Fall, R. (1995). Constructive activity and learning in collaborative small groups. Journal of educational psychology, 87, 406.

Wertsch, J. V., \& Stone, C. A. (1999). The concept of internalization in vygotsky's account of the genesis of higher mental functions. Lev Vygotsky: Critical assessments, 1, 363-380.

Wirth, J., \& Klieme, E. (2004). Computer-based assessment of problem solving competence. Assessment in Education: Principles, Policy, and Practice, 10, 329-345. 